\section{Diagnostic values of shear wave elastography and strain elastography for breast lesions}

\author{
HUIWEN JIANG ${ }^{1}$, XIAODAN YU ${ }^{2}$, LINA ZHANG ${ }^{3}$, \\ LINXIAO SONG ${ }^{4}$, XIUHUA GAO ${ }^{5}$
}

\section{ABSTRACT}

Background: Strain elastography (SE) and shear wave elastography (SWE) have high diagnostic yield for breast lesions, but the optimal parameters remain elusive. Aim: To evaluate the diagnostic yield of SWE and SE for breast lesions by multivariate logistic regression analysis. Material and Methods: A total of 132 patients with 164 breast tumors were enrolled. Breast lesions were classified with the breast imaging reporting and data system (BI-RADS). Maximum (Emax), mean (Emean) and standard deviation (Esd) of elastic modulus, lesion/fat elasticity ratio and elastographic classification were obtained by SWE. Strain ratio (SR) and elastographic score were obtained by SE. A multivariate logistic regression analysis was performed. The diagnostic efficiencies of BI-RADS classification, SWE, SE and their combination were compared plotting ROC curves. Results: There were 110 benign and 54 malignant lesions which had significantly different SWE and SE parameters. The parameters included in the logistic regression were Esd and elastographic classification obtained by SWE and the elastographic score obtained by SE. When combining SWE with SE, Esd, SR and SWE classification were included in the equation. The areas under ROC curves for BI-RADS classification, SWE, SE and their combination were 0.75, $0.88,0.79$ and 0.89 , respectively. Conclusions: The diagnostic value of SWE in combination with SE for breast lesions exceeded that of SE or SWE alone. Esd showed a good diagnostic yield when SWE was used alone or combined with SE.

(Rev Med Chile 2020; 148: 1239-1245)

Key words: Breast Diseases; Diagnosis; Elasticity Imaging Techniques.

\section{Elastografía de deformación y de onda cortante para el diagnóstico de lesiones mamarias}

Antecedentes: La elastografía de deformación (SE) y de onda cortante (SWE) son útiles para el diagnóstico de lesiones mamarias, pero falta definir los parámetros óptimos. Objetivo: Evaluar el valor diagnóstico de SE y SWE en lesiones mamarias usando una regresión logística multivariable. Material y Métodos: Ciento treinta $y$ dos pacientes con 164 tumores mamarios fueron evaluados, los que se clasificaron usando el sistema BI-RADS (breast imaging reporting and data system). El módulo elástico máximo, promedio y su desviación estándar (Esd), la razón entre la elasticidad de la lesión y de la grasa y la clasificación elastográfica se obtuvieron con SWE. La razón de deformación (SR) y el puntaje elastográfico se obtuvieron con SE. Se efectuó una regresión

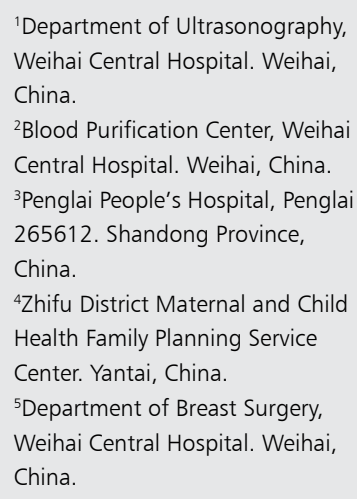

Financial support: This study was not financially supported.

Recibido el 21 de marzo de 2020 aceptado el 22 de septiembre de 2020.

Correspondence to:

Xiuhua Gao

Department of Breast Surgery, Weihai Central Hospital, Weihai 264400. Shandong Province,

China.

byronmccormickoup@yahoo.com 
logística y las eficiencias diagnósticas de la clasificación BI-RADS, SWE and $S E$ y su combinación se compararon usando curvas ROC (receiver operating characteristic curves). Resultados: Ciento diez lesiones fueron benignas y 54 malignas. Estas tenían parámetros SWE y SE significativamente diferentes. En la ecuación de regresión logística, se incluyeron la clasificación elastográfica y el Esd obtenidos por SWE y el puntaje elastográfico obtenido por SE. Cuando se combinó SWE y SE, se incluyeron en la ecuación el Esd, SR y la clasificación por SWE. Las áreas bajo la curva ROC para la clasificación BI-RADS, SWE y SE y la combinación de ambas fueron 0.75, 0.88, 079 y 0.89 respectivamente. Conclusiones: La combinación de SWE y SE tuvo un mejor rendimiento diagnóstico para lesiones mamarias que cada parámetro por separado. Esd tuvo un buen rendimiento diagnóstico cuando se utilizó SWE sola o combinada con SE.

Palabras clave: Diagnóstico; Diagnóstico por Imagen; Elasticidad; Enfermedades de la Mama.

A ccording to the data published by the International Agency for Research on Cancer, breast cancer has become the most common malignant tumor of females worldwide ${ }^{1}$. Similarly, breast cancer has seriously endangered female psychological and physical health in Chi$\mathrm{na}^{2}$. The mortality rate can be reduced through preclinical prevention, so, early screening and diagnosis are of great significance.

In recent years, biomechanics-based ultrasonic elastography has been verified to play crucial roles in the differentiation and diagnosis of benign and malignant breast lesions ${ }^{3-7}$. Strain elastography (SE) and shear wave elastography (SWE) have high diagnostic values for breast lesions, but the optimal parameters remain unclear. In this study, multivariate logistic regression analysis was used to determine the optimal parameters of SE or SWE alone and their combination for diagnosing breast lesions, and to compare their diagnostic efficiencies.

\section{Materials and Methods}

\section{Baseline clinical data}

A total of 132 female patients with breast tumors treated from January 2017 to December 2018 in our hospital were enrolled. Inclusion criteria: Routine ultrasonography revealed solid breast masses. Exclusion criteria: history of surgery or aspiration biopsy of mammary glands on the same side as that of lesions; implants in breasts; cystic lesions; maximum lesion diameter $>3 \mathrm{~cm}$. The 132 enrolled patients who were aged $15 \sim 81$ years old ([44.56 \pm 8.76$]$ on average) had 164 lesions. All lesions were pathologically confirmed (140 were surgically resected and 24 received thick needle biopsy), including 110 benign and 54 malignant lesions. This study was approved by the ethics committee of our hospital, and written informed consents have been obtained from all patients.

\section{Apparatus and Methods}

SuperSonic AixPlorer ultrasound system (France) was used with a probe frequency of $4 \sim 15 \mathrm{MHz}$. Each patient was placed in the supine position, with the upper limbs lying flat on both sides to fully expose the breasts. Lesions were observed by two experienced sonographers in the gray-scale mode and classified by using the breast imaging reporting and data system (BI-RADS). After switching to the SWE mode, the probe was placed on the body surface and left still for $3 \mathrm{~s}$ to collect elastic images. Q-box was utilized to obtain the elastic modulus values of lesions: maximum (Emax), mean (Emean), standard deviation (Esd) and lesion/fat elasticity ratio (Eratio). During the measurement of Emax, Emean and Esd, the lesions were covered by Q-box as much as possible. To measure Eratio, two Q-boxes $\left(2 \mathrm{~mm}^{2}\right)$ were placed on the hardest part of the lesion and surrounding fat tissue, respectively. The elastic images of lesions were classified into four types according to the four-color overlay pattern $^{8}$. Type I: Uniform blue image; type II: mostly blue image, with banded pseudo-color at the edge or inside; type III: local color change at the edge of lesion; type IV: uneven color changes inside tumor. Three frames of elastic images were collected from the same lesion and averaged.

SE was performed using Esaote My Lab Twice 
color Doppler ultrasound system (Italy) with a probe frequency of $4 \sim 13 \mathrm{MHz}$. In the same body position, the SE mode was selected with the same tangent plane as that of SWE. The region of interest was selected centering on the nodule, and the probe was applied with an appropriate external force and gently shaken. When the "spring" icon on the screen was displayed in green and stabilized, elastic images were acquired. Lesions were scored according to the modified 5-point scale 9.1 point: Lesion is entirety or mostly green; 2 points: lesion is red at the center and green all around; 3 points: green and red colors have similar proportions in the lesion range; 4 points: lesion is red overall or slightly green inside; 5 points: lesion and surrounding tissues are red, with or without green inside. The strain ratio (SR) of lesion to normal surrounding breast tissue at the same depth was measured. Three frames of image were selected for each lesion and averaged.

\section{Statistical analysis}

All data were statistically analyzed by SPSS 17.0 software. The quantitative data were subjected to the K-S normality test. The normally distributed quantitative data were expressed as mean \pm standard deviation, and the non-normally distributed ones were represented as median. The Mann-Whitney test was performed to compare the elastic parameters of benign and malignant breast lesions. The pathological results were utilized as the golden diagnostic criteria. Multivariate logistic regression analysis was conducted through maximum likelihood estimation to screen the most valuable parameters of SWE or SE alone and their combination for diagnosing breast lesions. $\mathrm{P}<0.05$ was considered statistically significant. Receiver operating characteristic (ROC) curve was plotted to analyze the diagnostic efficiency of each mode. The area under curve (AUC) values were compared with the $\mathrm{Z}$ test.

\section{Results}

\section{Pathological diagnosis and routine ultrasonography}

Of the 164 lesions, 110 were benign, including 33 adenoses, 7 cystic hyperplasias, 45 fibroadenomas, 3 galactoceles accompanied by calcification, 8 intraductal papillomas, 9 interstitial collagen fiber hyperplasias, 3 acute or chronic infiltrations of inflammatory cells and 2 hamartomas. There were 54 malignant lesions, including 31 invasive ductal carcinomas, 1 invasive lobular carcinoma, 10 intraductal carcinomas, 4 intraductal papillary carcinomas, 2 malignant lobulated tumors, 2 mucinous carcinomas, 3 invasive papillary carcinomas and 1 malignant lymphoma.

There were 42 lesions of BI-RADS category 3 , 62 of category 4A, 21 of category $4 \mathrm{~B}, 25$ of category $4 \mathrm{C}$ and 14 of category 5. BI-RADS categories 3 and $4 \mathrm{~A}$ were considered as benign masses, and categories $4 \mathrm{~B}$ and $4 \mathrm{C}$ were determined as malignant masses. The diagnostic sensitivity of BI-RADS classification was $78.18 \%$, the specificity was $70.37 \%$, and the accuracy was $75.61 \%$ (Table 1 ).

\section{SWE and SE parameters of benign and malig- nant lesions}

The benign lesion group had significantly lower SWE parameters (Emax, Emean, Esd, Eratio and SWE color pattern) and SE parameters (elastographic score and SR) than those of the malignant lesion group $(\mathrm{P}<0.001)$ (Table 2$)$.

Table 1. Prediction of breast lesion characteristics by SWE, SE and their combination

\begin{tabular}{|lcc|}
\hline $\begin{array}{l}\text { Prediction } \\
\text { method }\end{array}$ & $\begin{array}{c}\text { Pathological results } \\
\text { Benign }\end{array}$ & $\begin{array}{c}\text { Malignant } \\
\text { BI-RADS category }\end{array}$ \\
$\begin{array}{l}\text { Benign } \\
\text { Malignant }\end{array}$ & 86 & 16 \\
SWE & 24 & 38 \\
Benign & & \\
Malignant & 100 & 17 \\
SE & 10 & 37 \\
Benign & & \\
Malignant & 95 & 16 \\
SWE + SE & 18 & 38 \\
Benign & & \\
Malignant & 99 & 16 \\
\hline
\end{tabular}

BI-RADS categories 3 and $4 \mathrm{~A}$ were considered as benign lesions, and categories $4 \mathrm{~B}$ and $4 \mathrm{C}$ were determined as malignant lesions; SWE: malignant lesions were predicted by Esd and elastographic classification; SE: malignant lesions were predicted by elastographic score; SWE + SE: malignant lesions were predicted by Esd, SR and elastographic classification. 
Multivariate logistic regression analysis results

Multivariate logistic regression analysis was performed for the five parameters (Emax, Emean, Esd, Eratio and SWE color pattern) obtained by SWE (Table 3). Esd (X1) and elastographic classification (X2) were derived into the multivariate logistic regression equation which was $y(P)=-3.786+0.324 X 1+0.526 X 2$. Then the likelihood ratio test revealed statistical significance $\left(\chi^{2}=35.182, \mathrm{P}<0.001\right)$. The above mode was used to diagnose breast lesions, and a regression prediction probability of $\mathrm{P}>0.5$ for malignancy was assumed, giving 117 benign lesions (100 were pathologically benign) and 47 malignant ones (37 were pathologically malignant). The prediction sensitivity was $90.91 \%$, the specificity was $68.52 \%$, and the accuracy was $83.54 \%$.

Multivariate logistic regression analysis was conducted for the two parameters (elastographic score and SR) obtained by SE (Table 4). Elastographic score (X1) was derived into the multivariate logistic regression equation which was $y(P)=-5.489+1.343 X 1$. Then the likelihood ratio test revealed statistical significance $\left(\chi^{2}=31.276\right.$, $\mathrm{P}<0.001)$. The above mode was employed to diagnose breast lesions, and a regression prediction probability of $\mathrm{P}>0.5$ for malignancy was assumed, giving 111 benign lesions ( 95 were pathologically benign) and 56 malignant ones (38 were pathologically malignant). The prediction sensitivity was $85.59 \%$, the specificity was $70.37 \%$, and the accuracy was $81.10 \%$.

Afterwards, multivariate logistic regression analysis was carried out for the five (Emax, Emean, Esd, Eratio and SWE color pattern) and two parameters (elastographic score and SR) obtained by SWE and SE, respectively (Table 5). Esd (X1), SR (X2) and elastographic classification (X3) were

Table 2. SWE and SE parameters of benign and malignant lesions

\begin{tabular}{|lccc|}
\hline & Benign $(\mathbf{n}=\mathbf{1 1 0})$ & Malignant $(\mathbf{n}=\mathbf{5 4})$ & P \\
\hline Emax $(\mathrm{kPa})$ & $26.28(21.69-3.24)$ & $60.39(37.02-135.28)$ & $<0.001$ \\
Emean $(\mathrm{kPa})$ & $14.36(11.79-16.81)$ & $25.26(17.02-35.28)$ & $<0.001$ \\
Esd $(\mathrm{kPa})$ & $3.87(2.81-5.64)$ & $11.08(7.03-23.14)$ & $<0.001$ \\
Eratio & $2.59(1.90-3.49)$ & $6.54(3.45-11.89)$ & $<0.001$ \\
SWE color pattern & $1.54 \pm 0.24$ & $2.79 \pm 0.48$ & $<0.001$ \\
SR & $1.51(1.13-1.80)$ & $2.09(1.53-2.41)$ & $<0.001$ \\
Elastographic score & $2.85 \pm 0.35$ & $3.74 \pm 0.42$ & $<0.001$ \\
\hline
\end{tabular}

Table 3. Logistic regression analysis results of SWE parameters

\begin{tabular}{|lcccccc|}
\hline Variable & B & Sx & Wals & Df & Sig & Exp(B) \\
\hline Esd & 0.219 & 0.058 & 13.219 & 1 & 0.000 & 1.232 \\
\hline SWE color pattern & 0.463 & 0.218 & 4.318 & 1 & 0.031 & 1.576 \\
\hline
\end{tabular}

Likelihood ratio revealed statistical significance $\left(\chi^{2}=35.182, P<0.001\right)$.

Table 4. Logistic regression analysis results of SE parameters

\begin{tabular}{|lcccccc|}
\hline Variable & B & Sx & Wals & Df & Sig & Exp(B) \\
Elastographic score & 1.298 & 0.267 & 22.198 & 1 & 0.000 & 3.281 \\
\hline
\end{tabular}

Likelihood ratio revealed statistical significance $\left(\chi^{2}=31.276, \mathrm{P}<0.001\right)$. 
Table 5. Logistic regression analysis results of SWE + SE parameters

\begin{tabular}{|lcccccc|}
\hline Variable & B & Sx & Wals & Df & Sig & Exp(B) \\
\hline Esd & 0.202 & 0.057 & 10.872 & 1 & 0.000 & 1.224 \\
\hline SR & 0.961 & 0.391 & 5.927 & 1 & 0.014 & 2.598 \\
\hline SWE color pattern & 0.453 & 0.229 & 4.013 & 1 & 0.041 & 1.578 \\
\hline
\end{tabular}

Likelihood ratio revealed statistical significance $\left(\chi^{2}=75.428, P<0.001\right)$.

derived into the multivariate logistic regression equation which was $\mathrm{y}(\mathrm{P})=-4.762+0.212 \mathrm{X} 1+$ $0.946 \mathrm{X} 2+0.462 \mathrm{X} 3$. The likelihood ratio test revealed statistical significance $\left(\chi^{2}=75.428, \mathrm{P}<0.001\right)$. This mode was utilized to diagnose breast lesions, and a regression prediction probability of $\mathrm{P}>0.5$ for malignancy was assumed, giving 115 benign lesions ( 99 were pathologically benign) and 49 malignant ones (38 were pathologically malignant). The prediction sensitivity was $90.00 \%$, the specificity was $70.37 \%$, and the accuracy was $83.54 \%$.

\section{ROC curve analysis results}

ROC curve was plotted by using the pathological results as the golden criteria, BI-RADS categories 3 and $4 \mathrm{~A}$ as benign lesions, and categories $4 \mathrm{~B}$ and $4 \mathrm{C}$ as malignant lesions. The resulting AUC was 0.751 (95\% CI: 0.658 0.814). AUCs for SWE, SE and their combination were 0.875 (95\% CI: 0.80 0.935), 0.785 (95\% CI: 0.701 0.875) and 0.889 (95\% CI: 0.83 0.951), respectively (Figure 1). AUC of SWE in combination with SE was significantly higher than that of SE alone $(\mathrm{P}<0.05)$ and slightly higher than that of SWE alone $(\mathrm{P}>0.05)$.

\section{Discussion}

Ultrasonic elastography, which was first proposed by Ophir et al. in 1991, has become a milestone in the field of ultrasonographic diagnosis ${ }^{5}$. Currently, SE and SWE are mainly employed to diagnose breast lesions. SE applies a constant pressure to the tissue for detection to cause deformation that is then calculated and displayed, which is static and semi-quantitative ${ }^{6}$. SWE generates an ultrasonic shear wave through transducer, continuously focuses at different depths of tissue, records the small displacement of tissue caused by wave propagation using ultra-hi-

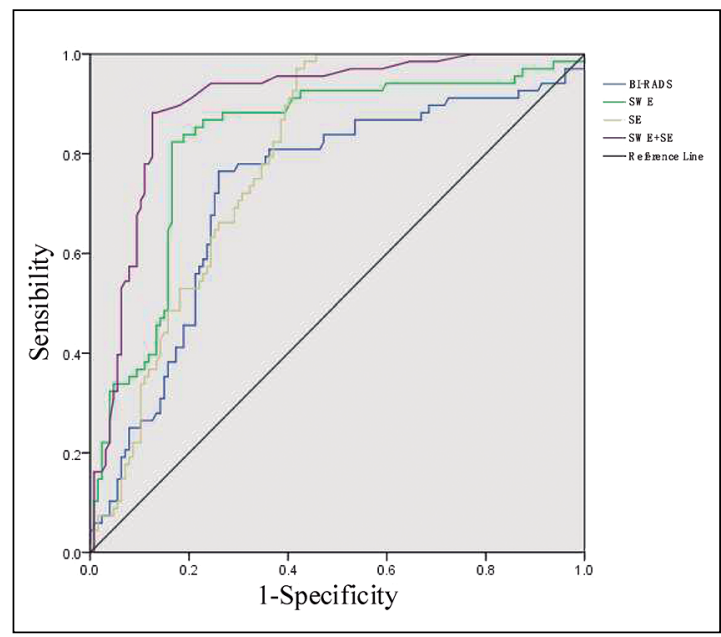

Figure 1. ROC curve analysis results for BI-RADS classification, SWE, SE and their combination.

gh speed imaging, and measures the speed of shear wave-induced spot movement by a quantitative analysis software, finally giving the absolute value of tissue elasticity ${ }^{4,7}$.

Breast elastography is based on the close relationship between hardness of lesion and its internal pathological structure ${ }^{10}$. The SWE parameters (Emax, Emean, Esd, Eratio and elastographic classification) and SE parameters (elastographic score and SR) of benign and malignant breast lesions were significantly different, suggesting that the lesions had significantly different hardnesses. SWE can predict the pathological type of breast cancer. When the cutoff value of average Emax is set at $70.7 \mathrm{kPa}$, the sensitivity for diagnosing invasive breast cancer is $72.0 \%$ and the specificity is $65.7 \%{ }^{11}$. However, SWE also gives false positive or negative results in identifying benign and malignant breast masses. Han et al. reported that when Emax was $<61.45 \mathrm{kPa}$, three cases of malignant 
masses were misdiagnosed as benign ones, because lesion tissues cannot be completely penetrated by shear wave due to limited region of interest ${ }^{12}$.

The hardness of breast mass can be obtained by both SWE and $\mathrm{SE}^{6,13}$. Although the lesion elastographic parameters obtained by SWE and SE have diagnostic values, both of them have limitations $s^{6,7,13}$. Esd represents the distribution of internal elastic modulus of a lesion in different regions, and a higher value means a less uniform distribution. For the differentiation of benign and malignant breast lesions, homogeneity may be more important than hardness ${ }^{14}$. SWE image is color-coded for the absolute value of tissue elastic modulus, which can visualize the hardness distribution and difference. Under standard conditions, the elastographic images of different lesions can be compared ${ }^{8}$. Our analyses showed that SWE classification reflected the overall characteristics of lesion elasticity, and had more diagnostic advantages than those of Emax and Emean. As to SE, the score was derived into the equation, verifying its high value in the differentiation of benign and malignant breast lesions. Until now, SWE has seldom been combined with SE to diagnose benign and malignant breast lesions. For SWE in combination with SE herein, Esd, SR and SWE classification were sequentially derived into the multivariate logistic regression equation, proving the diagnostic advantages of Esd and SWE classification. Notably, SR instead of SE score was derived into the equation, which may be attributed to the similar diagnostic value of the SE ratio method to that of the modified 5-point scale $^{15}$. When combined with SWE, Esd and SWE classification can reflect the overall characteristics of lesion elasticity, and SR represents the relative hardnesses of lesion and surrounding tissue, so the diagnostic efficiency of SR is higher. ROC curve is commonly used to analyze the diagnostic efficiency of a detection method, and a larger AUC suggests a higher efficiency. In this study, the diagnostic efficiencies of SWE and SE for benign and malignant breast lesions both exceeded that of BI-RADS classification. The diagnostic efficiency of SWE in combination with SE was significantly higher than that of SE alone and slightly higher than that of SWE alone. Hence, diagnosis using SWE in combination with SE was not markedly superior to that using SWE alone.

Herein, the sensitivities of SWE, SE and their combination for diagnosing breast lesions were all high, but their specificities were not high enough, possibly due to histopathological complexity and crossover between the hardnesses of benign and malignant lesions ${ }^{16}$. There were soft malignant lesions such as medullary, mucinous and necrotic invasive ductal carcinomas, and hard benign lesions such as hyaline fibroma and fat necrosis. In-depth studies with larger sample sizes involving other factors such as clinical characteristics of patients with lesions are still in need to increase the diagnostic efficiency.

\section{Conclusions}

In summary, the diagnostic value of SWE in combination with SE for breast lesion exceeded that of SE or SWE alone. Multivariate logistic regression analysis revealed that Esd showed diagnostic advantages for both SWE alone and SWE combined with SE.

\section{References}

1. Lauby-Secretan B, Scoccianti C, Loomis D, Benbrahim-Tallaa L, Bouvard V, Bianchini F, et al. Breast-cancer screening-viewpoint of the IARC Working Group. New Engl J Med 2015; 372 (24): 2353-8.

2. Li T, Mello-Thoms C, Brennan PC. Descriptive epidemiology of breast cancer in China: incidence, mortality, survival and prevalence. Breast Cancer Res Treat 2016; 159 (3): 395-406.

3. Hao SY, Ou B, Li LJ, Peng YL, Wang Y, Liu LS, et al. Could ultrasonic elastography help the diagnosis of breast cancer with the usage of sonographic BI-RADS classification? Eur J Radiol 2015; 84 (12): 2492-500.

4. Yağcı B, Toslak IE, Çekiç B, Öz M, Karakaş BR, Akdemir $\mathrm{M}$, et al. Differentiation between idiopathic granulomatous mastitis and malignant breast lesions using strain ratio on ultrasonic elastography. Diagn Interv Imaging 2017; 98 (10): 685-91.

5. Mu WJ, Zhong WJ, Yao JY, Li LJ, Peng YL, Wang Y, et al. Ultrasonic elastography research based on a multicenter study: Adding strain ratio after 5-point scoring evaluation or not. PloS One 2016; 11 (2): e0148330.

6. Ma Y, Zhang S, Li J, Li J, Kang Y, Ren W. Comparison of strain and shear-wave ultrasounic elastography in predicting the pathological response to neoadjuvant chemotherapy in breast cancers. Eur Radiol 2017; 27 (6): 2282-91. 
7. Faruk T, Islam MK, Arefin S, Haq MZ. The journey of elastography: background, current status, and future possibilities in breast cancer diagnosis. Clin Breast Cancer 2015; 15 (5): 313-24.

8. Youk JH, Gweon HM, Son EJ. Shear-wave elastography in breast ultrasonography: the state of the art. Ultrasonography 2017; 36 (4): 300-9.

9. Park CS, Kim SH, Jung NY, Choi JJ, Kang BJ, Jung HS. Interobserver variability of ultrasound elastography and the ultrasound BI-RADS lexicon of breast lesions. Breast Cancer 2015; 22 (2): 153-60.

10. Ganau S, Andreu FJ, Escribano F, Martín A, Tortajada L, Villajos M, et al. Shear-wave elastography and immunohistochemical profiles in invasive breast cancer: evaluation of maximum and mean elasticity values. Eur J Radiol 2015; 84 (4): 617-22.

11. Bae JS, Chang JM, Lee SH, Shin SU, Moon WK. Prediction of invasive breast cancer using shear-wave elastography in patients with biopsy-confirmed ductal carcinoma in situ. Eur Radiol 2017; 27 (1): 7-15.

12. Han LS, Cui GH, Li XQ, Yu P. [Comparative study of shear wave elastography and strain elastography in differential diagnosis of benign and malignant breast masses]. J Modern Med Health 2019; 35 (3): 353-6.

13. Berg WA, Mendelson EB, Cosgrove DO, Doré CJ, Gay J, Henry JP, et al. Quantitative Maximum Shear-Wave Stiffness of Breast Masses as a Predictor of Histopathologic Severity. AJR Am J Roentgenol 2015; 205 (2): 448-55.

14. Barr RG, Nakashima K, Amy D, Cosgrove D, Farrokh A, Schafer F, et al. WFUMB guidelines and recommendations for clinical use of ultrasound elastography: Part 2: breast. Ultrasound Med Biol 2015; 41 (5): 1148-60.

15. Zhang L, Dong YJ, Zhou JQ, Jia XH, Li S, Zhan WW. Similar Reproducibility for Strain and Shear Wave Elastography in Breast Mass Evaluation: A Prospective Study Using the Same Ultrasound System. Ultrasound Med Biol 2020; 46 (4): 981-91.

16. Ohta T, Nakata N, Nishioka M, Igarashi T, Fukuda K. Quantitative differentiation of benign and malignant mammographic circumscribed masses using intensity histograms. Jpn J Radiol 2015; 33 (9): 559-65. 